\title{
Lamellar Icthyosis: A Clinical Dilemma
}

\author{
Amar Verma ${ }^{1}$, Rani Manisha ${ }^{2}$, R. K. Narayan ${ }^{3}$ \\ ${ }^{1}$ Professor, Department of Paediatrics \& Neonatology, Rajendra Institute of Medical Sciences, ${ }^{2}$ Junior Resident (Academic), Rajendra Institute of Medical Sciences, ${ }^{3}$ Senior \\ Resident, All India Institute of Medical Sciences.
}

\section{Abstract}

Congenital Autosomal recessive ichthyosis is a heterogenous group of disorders that are present at birth with generalized involvement of skin and lack of other organ systems. This case report presents involvement of respiratory system and its management with outcome in a rather uncommon presentation of lamellar icthyosis.

Keywords: Lamellar Icthyosis, Respiratory Distress, Ectropion, Epiphora.

Corresponding Author: Dr. Amar Verma, 6C Jyoti Vihar, Harmu Road, Ranchi, Jharkhand-834-001.

Received: August 2018

Accepted: September 2018

\section{Introduction}

Lamellar ichthyosis is a severe form of icthyosis. Mostly it is autosomal recessive. Its incidence is less than 1 in 3 lakhs. ${ }^{[1]}$ Other types of icthyosis are Icthyosis vulgaris, Epidermolytic hyperkeratosis, Congenital ecthyosiform eryhtroderma,Sjogren Larsson syndrome, Rud's syndrome, Refsum,s disease, Icthyosis linearis circumflexa etc. All types of icthyosis presents from or shortly after birth. Diagnosis of lamellar ichthyosis is based on the history of collodion membrane at birth which is shed soon after birth. The characteristic appearance of scales especially on shins. ${ }^{[2]}$ Lamellar ichthyosis evolves into large, quadrilateral, dark scales that are free at the edges and adherent at the center. Scaling is often pronounced and involves the entire body surface, including flexural surfaces. The face is often markedly involved, including ectropion and small, crumpled ears. The palms and soles are generally hyperkeratotic. The hair may be sparse and fine, but the teeth and mucosal surfaces are normal. ${ }^{[3]}$ The nails may be stippled, ridged and thickened with associated subungual hyperkeratosis. The condition is unremitting and persists throughout life.

\section{Case Report}

A 14 years old male patient reported in Department of Pediatrics, Rajendra Institute of Medical Sciences, Ranchi with complaint of difficulty in breathing since 7 days which was not associated with any history of fever or cough. Breathing difficulty was of sudden onset, slowly progressive, affected his daily activities, more in lying down position than sitting posture. There was no similar history of breathing difficulty in past. Detailed history revealed presence of dry scaly skin all over body since birth. The dryness improves in winter and worsens in summers. There was history of decreased sweating with mild pruritis. The patient was born out of non-consanguinous marriage. His growth and development milestones were normal. Her parents and siblings are apparently healthy. History was suggestive of colloidon membrane present and premature rupture of membrane was present. Earlier patient was diagnosed in July, 2012 with lamellar icthyosis at dermatology department, CMC Vellore.

Investigations done at CMC Vellore showed ---

Parathyroid hormone $249.9 \mathrm{pg} / \mathrm{ml}$

Serum chloride $102 \mathrm{mmol} / \mathrm{l}$, Serum sodium $134 \mathrm{mmol} / \mathrm{l}$, Serum potassium $4.3 \mathrm{mmol} / \mathrm{l}$, Serum bicarbonate $21 \mathrm{mmol} / \mathrm{l}$

Total bilirubin $0.5 \mathrm{mg} \%$, direct bilirubin $0.2 \%$

Total Protein $7.4 \mathrm{~g} \%$, total albumin $4.2 \%$

SGOT 17 U/L, SGPT $10 \mathrm{U} / \mathrm{L}$, ALP $176 \mathrm{U} / \mathrm{L}$

Serum Creatinine $0.64 \mathrm{mg} \%$

Total cholesterol $111 \mathrm{mg} \%$, serum triglyceride86 mg\%, HDL $33 \%$, LDL $60 \%$

$\mathrm{Hb} 10.4$ gm\%, total WBC $12,600 / \mathrm{mm} 3$

N63\%/L22\%/E 10\%/M 5\%/ B 0\% with no nucleated RBCs

He did not report back to CMC Vellore for followup after taking isotretinion for 15 days only.

Currently patient reported at our Hospital with respiratory distress present even at rest (orthpnoea) without tachycardia and chest was clear. There was absence of organomegaly. CNS was within normal limits. Oxygen saturation was 96 percent at room air with no fever or lymphadenopathy. There was presence of dry skin with large scales all over body with minimal sparing of the perioral area.

The scales were dark brown in colour, polygonal in shape, large in size, thick and adherent to skin prominently over shins. Palmoplantaer keratoderma was present. External 


\section{Verma et al; Lamellar Jcthyasis}

auditory meatus was hyperpigmentation and scaling was present. He was not able to stretch his fingers completely and there was minimal flexor contracture. Pallor and leuconychia was present. Diffuse scaling was present over scalp. Eyelashes of lower eyelids were decreased and there was decrease in eyebrows and scalp hairs. Discoloration of teeth was present.

Ocular examination shows scaly lids. Adnexa was found with bilateral ectropion accompanied with epiphora. There was incomplete closure of eyelids due to contracture along with presence of bell's phenomenon. Visual acuity was also decreased with $6 / 18$ in left and 6/12 in right.

Patient was admitted and treated with oxygenation, intravenous antibiotics, nebulisation with levosalbutamol and budesonide.

Patient was further investigated to rule out any cardiac or pulmonary causes of breathing difficulty. Investigations included complete blood count and urine examination was within normal limits. Mantoux test was negative. Spirometry showed grade III obstruction. Chest x-ray reported nothing significant. Electrocardiogram and echocardiography was within normal limit. Conservative treatment led to relief of respiratory distress. Patient was discharged with emollients, keratolytics, antihistaminic, vitamin $\Lambda$, appropriate eyedrops with advice for follow-up. Patient was followed up after 21 days \& reported with similar episode of breathing difficulty of 20 min duration precipitated by cycling a distance of around 100 meters, relieved on taking rest. Patient was advised the same treatment to continue and advised for regular follow-up.

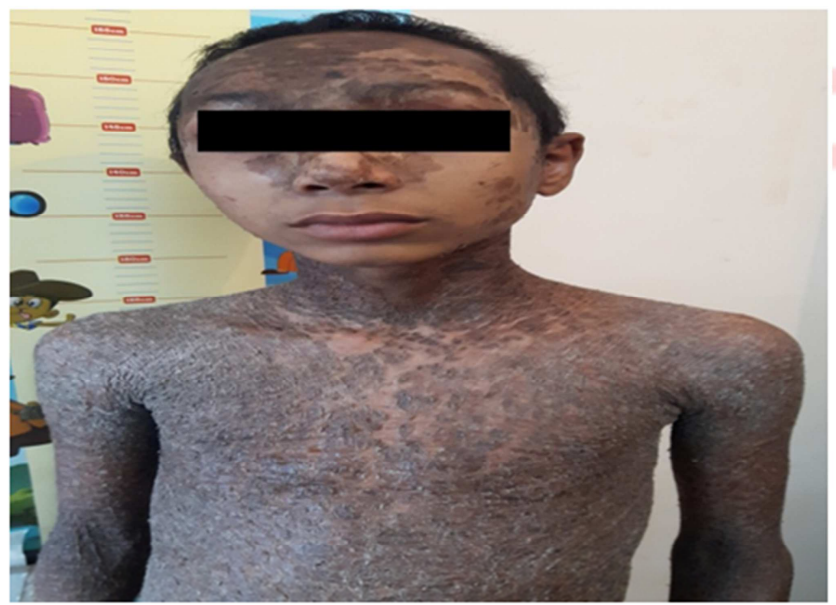

Figure 1: 14 years old boy with generalized icthyosis

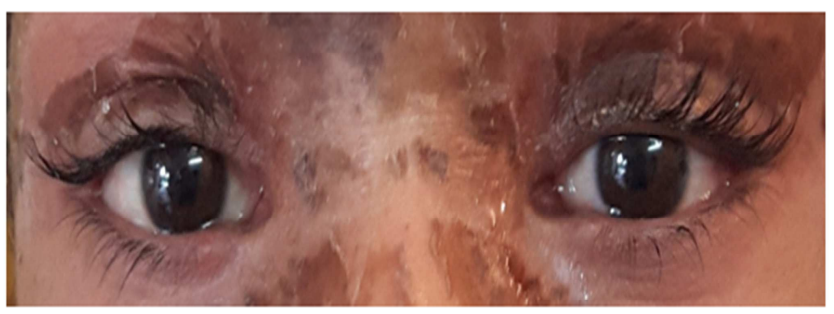

Figure 2: Ectropion of both eyes with epiphora in 14 years old boy with lamellar icthyosis

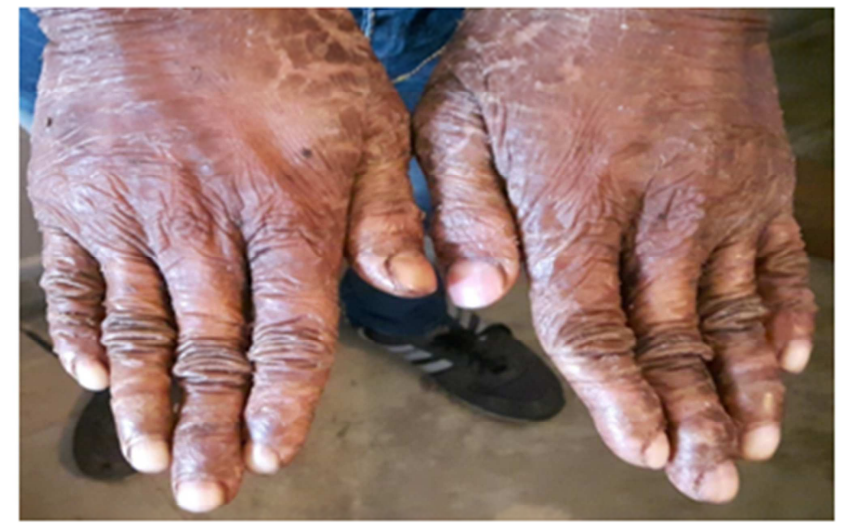

Figure 3: Flexion contracture of fingers in 14 years old boy with lamellar icthyosis

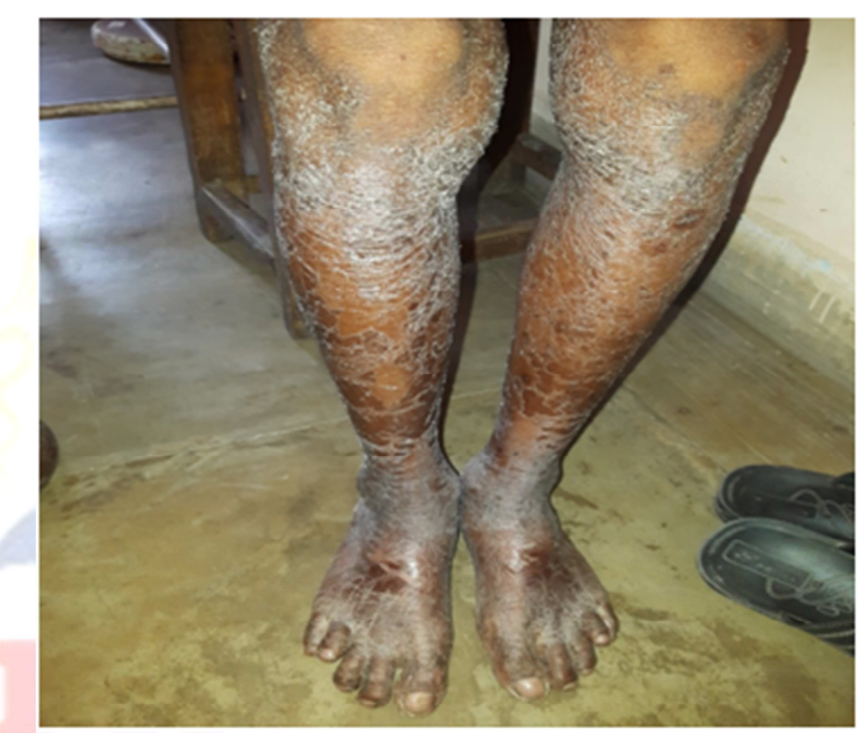

Figure 4: Large brown, thick, adherent scales over shins in 14 years old boy with lamellar icthyosis

\section{Discussion \& Conclusion}

The term ichthyosis is derived from the Greek word 'ichthys" meaning "fish" and refers to the similarity in appearance of the skin to fish scales. Early reports of ichthyosis in the Indian and Chinese literature dates back to several hundred years. ${ }^{[4]}$

Six genes have been identified that cause non-HI ARCI: TGM (the gene encoding transglutaminase), ABCA12, NIPAL4 (also known as ICHTHYIN), CYP4F22, and the lipoxygenase genes ALOX12B and ALOXE3. Transglutaminase mutations lead to abnormalities in the cornified envelope, whereas defects in ABCA12 cause abnormal lipid transport and those in CYP4F22 produce abnormal lamellar granules. The lipoxygenases are likely to play a role in epidermal barrier formation by affecting lipid metabolism. ${ }^{[2]}$ Epidermal kinetic studies show increased epidermal mitotic activity and a rapid epidermal cell transit time. Scales are due to increased proliferation of epidermal cells. 


\section{Verma et al; Lamellar Icthyasis}

Histopathology shows marked hyperkeratosis, hypergranulosis and moderate acanthosis with prominent rete ridges. Mitotic figures in the epidermis are frequent. A mild perivascular infiltrate is noted in the upper dermis.

The clinical features of lamellar icthyosis are typical \& easily clinically identifiable. Interprofessional coordinated management of dermatologist, paediatrician, geneticist, opthamologist and physiotherapist play an important role in managing such cases. The management of a typical case is aimed at decreasing symptoms and include emollients (petrolatum, coconut oil, alpha hydroxyl acetic acid), Keratolytics containing salicylates with propylene glycol and local and systemic retinoids. ${ }^{[5]}$

The present case is unique in having lamellar icthyosis with respiratory systemic involvement as evidenced by grade III obstruction of airways in Spirometry. Such case should be managed with focus on relieving respiratory symptoms with supportive treatment followed by regular monitoring of respiratory functions. Chest infections should be prevented with proper immunization and should be promptly managed with antibiotics if occurs. Nutrional supplements especially vitamin A should be provided. Efforts should be made to prevent respiratory complications and respiratory failure leading to morbidity and mortality.

\section{References}

1. Sandler B, Hashimoto K. Collodion baby and lamellar ichthyosis. J. Cutan. Pathol. 1998;25(2):116-21.

2. Traupe H. The ichthyosis: a guide to clinical diagnosis, genetic counseling, and therapy. Berlin: Springer Verlag, 1989: 111-34

3. Nelson Book of Prdiatrics, page no. 3171, first south east Asian edition, 2015

4. Hemandez-Martin A, Cuadrado-Corrales N, Cirla-Abad S, Arias-Palomo D, Mascaro-Galy JM, Escamez MJ, et al. X-linked ichthyosis along with recessive dystrophic epidermolysis bullosa in the same patient. Dermatology. 2010; 221:113-16.

5. Oji V, Tadini G, Akiyama M, Blanchet Bardon C, Bodemer C, Bourrat $\mathrm{E}$, et al. Revised nomenclature and classification of inherited ichthyoses: Results of the First Ichthyosis Consensus Conference in Sorze 2009. J. Am. Acad. Dermatol. 2010; 63(4):607-41.

Copyright: () the author(s), publisher. Asian Journal of Clinical Pediatrics and Neonatology is an Official Publication of "Society for Health Care \& Research Development". It is an open-access article distributed under the terms of the Creative Commons Attribution NonCommercial License, which permits unrestricted non-commercial use, distribution, and reproduction in any medium, provided the original work is properly cited.

How to cite this article: Verma A, Manisha R, Narayan RK. Lamellar Icthyosis: A Clinical Dilemma. Asian J. Clin. Pediatr. Neonatol.2018;6(2):4-6.

DOI: dx.doi.org/10.21276/ajcpn.2018.6.2.2

Source of Support: Nil, Conflict of Interest: None declared. 